\title{
Assessment of Thyroid Functions in Critically Ill Patients
}

\author{
Authors \\ Rohit Herekar ${ }^{1}$, G.H. Tilve ${ }^{2}$ \\ ${ }^{1}$ Department of Medicine Government Medical College Miraj \\ ${ }^{2}$ Department of Medicine Saraswati Medical foundation Kolhapur \\ Corresponding Author \\ Dr Rohit Herekar \\ Assistant Professor GMC Miraj, India \\ Email-drrohitherekar@gmail.com,8605512787
}

\begin{abstract}
Background: The thyroid function tests triiodothyronine, thyroxine and thyrotropin are abnormal in critical illness. The pattern of abnormality depends on the severity of disease and thyroidal hormones can help in prognosis of patients.

Methods: 50 Critically ill patients were enrolled in study with inclusion and exclusion criterias. The clinical, lab profile along with T3, T4 and their free levels along with TSH were measured.

Results: The thyroid functions were abnormal in $86 \%$ of the critically ill patients. The low T3 syndrome constituted most common abnormality (44.18\%). In the thyroid functions T3, free T3, T4 and Free T4 were deranged, the values of TSH were normal. In thyroid function the low T3 T4 syndrome was associated with mortality and thyroid hormones T3, T4, free T4 were associated with poor outcome of the patients.

Conclusions: The thyroid functions are abnormal in critically ill patients and it is worthwhile to associate the outcome of critically ill patients depending on the abnormality of thyroid functions.
\end{abstract}

\section{INTRODUCTION}

Abnormalities of thyroid hormone concentrations are seen commonly in a wide variety of nonthyroidal illnesses (NTI) and in patients who are acutely ill. ${ }^{(2,5,7)}$, resulting in abnormal triiodothyronine, thyroxine, and thyroid stimulating hormone concentrations. ${ }^{(1)}$

A decreased level of serum total Triiodothyronine $\left(T_{3}\right)$ is the most common function abnormality in patients with acute illness ${ }^{(3)}$ and can be detected within 2 hours after the onset of severe physical stress $^{(8)}$ and is seen in 40-60\% of the cases. As the severity of illness progresses, there is gradual development of a more complex syndrome associated with low levels of $\mathrm{T}_{3}$ and thyroxine $\left(\mathrm{T}_{4}\right) .{ }^{(6,10)}$ Altered thyroid hormone levels have been reported in starvation, ${ }^{(11,12)}$ acute and chronic medical illnesses, ${ }^{(13,14,15)}$ bone marrow transplantation, ${ }^{(16)}$ surgery, ${ }^{(17)}$ trauma, ${ }^{(18)}$ and, in fact, can be seen in any severe systemic illness. ${ }^{(19)}$ The pattern of physiologic changes is referred as Non thyroidal illness syndrome without taking into consideration metabolic profile as in Euthyroid sick syndrome. (1,9,21) $^{-}$

\section{MATERIALS AND METHODS}

This was a prospective study after approval from ethical committee admitted in ICU of Saraswati Hospital and Medical centre. The patients or their 
relatives provided written informed consent before enrollment. 50 patients with critical illness without known thyroidal illness were selected. The general information and examintation was done and for severity APACHE II score was calculated. On admission blood sample collected for thyroid function tests and. TSH, T3, FreeT3, T4, Free T4 was measured by Acculitemicroplate CLIA assay. (chemiluminescence immunoassay) method.

Low T3 syndrome: reduced levels of free T3 /total T3

Low T4 syndrome: reduced levels of free T4 / total $\mathrm{T} 4$

Low T3/T4 syndrome: reduced levels of T3 (total / free T3) \& T4 (total/ freeT4)

Hypothyroidism: TSH $>10 \mathrm{uIU} / \mathrm{ml}$ with low levels of free T4 +/- low levels of T3

Hyperthyroidism: TSH $<0.10 \mathrm{uIU} / \mathrm{ml}+$ low levels of T3, T4

Subclinical hypothyroidism: Raised TSH with normal thyroid hormonal levels

Subclinical hyperthyroidism: Decreased TSH with normal thyroid hormone levels.

The patients were divided into two groups. The first group consisted of survivors and second group of non survivors or expired patients during hospital stay. The Serum TSH, T3, free T3, T4, Free T4, APACHE II were compared. The individual thyroid functions were compared with outcome of the patients with Chi square test (Yate 's correction applied whenever necessary). The relative risk of individual thyroid functions was determined with odds ratio. The thyroid abnormalities were grouped into syndromes and using pooled data the effect on outcome was calculated.

\section{OBSERVATION}

A total of 50 patients were enrolled consecutively in the present study. In these studies 27 were females and 23 were male

\section{Thyrotropin (TSH)}

Out of the total study group, 7 (16.27\%) out of 50 displayed abnormal TSH. Although the population of individuals with abnormal TSH was higher in group $2(20 \%)$ as compared to group $1(12.5 \%)$. This difference was not statistically significant with chi square test with $X^{2}=0.01 \mathrm{p}>0.05$.

Table 1- TSH and outcome

\begin{tabular}{|c|c|c|c|}
\hline TSH & Survived & Expired & Total \\
\hline Normal & 35 & 8 & 43 \\
\hline Abnormal & 5 & 2 & 7 \\
\hline Total & 40 & 10 & 50 \\
\hline
\end{tabular}

\section{Triiodothyronine (T3)}

In the study group 18 patients had abnormalities T3 that constituted $36 \%$ of total cases. In expired group $70 \%$ had abnormal values compare to 27.5 $\%$ in survived patients. This difference was statistically significant with $\mathrm{X} 2=6.27, \mathrm{p}<0.05$.

Table 2- T3 and outcome

\begin{tabular}{|c|c|c|c|}
\hline T3 & Survived & Expired & Total \\
\hline Normal & 29 & 3 & 32 \\
\hline Abnormal & 11 & 7 & 18 \\
\hline Total & 40 & 10 & 50 \\
\hline
\end{tabular}

\section{Free T3}

Out of the total patients 39 patients $(78 \%)$ had abnormal thyroid values. Although the population of individuals with abnormal free $\mathrm{T} 3$ is higher in group $2(90 \%)$ as compared to group $1(75 \%)$. This difference was not statistically significant with chi square test with $X^{2}=0.35 p>0.05$.

Table 3- Free T3 outcome

\begin{tabular}{|c|c|c|c|}
\hline Free T3 & Survived & Expired & Total \\
\hline Normal & 10 & 1 & 11 \\
\hline Abnormal & 30 & 9 & 39 \\
\hline Total & 40 & 10 & 50 \\
\hline
\end{tabular}

\section{Thyroxine (T4)}

In the study population 19 patients $(38 \%)$ of the total population had abnormal T4 values, and in non survival group had $80 \%$ abnormal values compared to $27.5 \%$ in survival group. This difference was statistically significant with $\mathrm{X} 2=$ $9.35, \mathrm{p}<0.05$. 
Table 4- T4 and outcome

\begin{tabular}{|c|c|c|c|}
\hline T4 & Survived & Expired & Total \\
\hline Normal & 29 & 2 & 31 \\
\hline Abnormal & 11 & 8 & 19 \\
\hline Total & 40 & 10 & 50 \\
\hline
\end{tabular}

\section{Free T4}

In the study population $16 \quad(32 \%)$ out of total patients had abnormal values. In the non survival group $90 \%$ had abnormal values as compared to $17.5 \%$ of the survivors. This difference is statistically significant with X2 $=19.3, \mathrm{p}<0.05$.

Table 5- Free T4 and outcome

\begin{tabular}{|c|c|c|c|}
\hline Free T4 & Survived & Expired & Total \\
\hline Normal & 33 & 1 & 34 \\
\hline Abnormal & 7 & 9 & 16 \\
\hline Total & 40 & 10 & 50 \\
\hline
\end{tabular}

\section{Thyroid function and outcome}

The below table shows relative risk determined by odds ratio. In the patients values of $\mathrm{T} 3, \mathrm{~T} 4$, and free $\mathrm{T} 4$ in ascending order were associated with poor outcome in the patients.

Table 6 - Thyroid function and relative risk

\begin{tabular}{|c|c|}
\hline Thyroid Function & Relative Risk \\
\hline TSH & 1.53 \\
\hline T3 & 4.15 \\
\hline Free T3 & 2.54 \\
\hline T4 & 6.52 \\
\hline Free T4 & 30.6 \\
\hline
\end{tabular}

\section{Syndromes in Critically ill:}

Out of the 50 patients studied

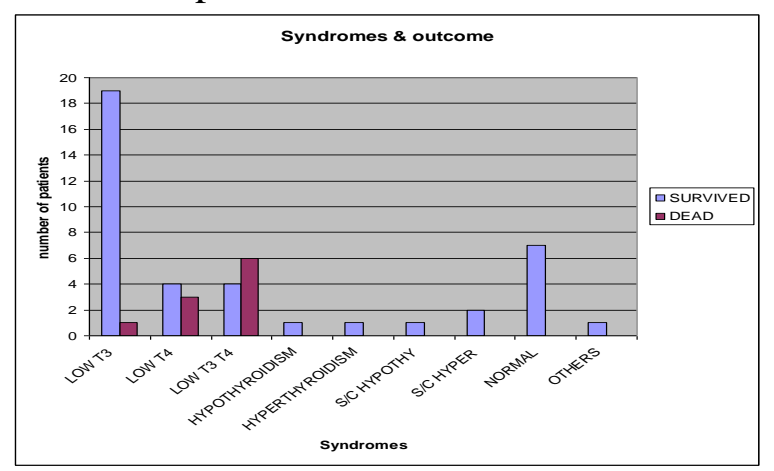

Figure 1.Syndromes in critically ill cases
Out of the syndromes the Low T3, low T4 and Low T3 T4 constituted all the patients of the non survivor group. The low T3 T4 group constituted $60 \%$ of expired population. Applying Chi square test to pooled data the association of Low T3 T4 syndrome with death was statistically significant (d.f. $=1, \mathrm{X} 2=5.23$ )

Table 7 Important syndromes

\begin{tabular}{|c|c|c|c|}
\hline Syndromes & Survived & Died & Total \\
\hline Low T3 & 19 & 1 & 20 \\
\hline Low T4 & 4 & 3 & 7 \\
\hline Low T3 T4 & 4 & 6 & 10 \\
\hline Total & 27 & 10 & 37 \\
\hline
\end{tabular}

\section{DISCUSSION}

The present study was carried out on 50 critically ill patients. On admission serum for thyroid functions Thyrotropin, Total and free Triiodothyronine and total and free thyroxine was collected. The distribution of thyroid hormones in the population was studied in two groups (survivor group and non survivors) and grouped in syndromes. Out of the 50 patients, 10 patients had expired during hospitalization.

The values of the thyroid functions were combined and grouped in various syndromes and compared with outcome.

\section{Thyrotropin: (TSH)}

The distribution of TSH in the study population in two different groups was not significant and also $16.27 \%$ displayed deranged TSH which was not related to the outcome of patients.

\section{Triiodothyronine: (T3)}

In the study population the non survivors had 70 $\%$ lower values compared to $27.5 \%$ in survivors. The value of T3 correlated with the poor outcome of patients $(\mathrm{RR}=4.15)$.

\section{Free T3}

The abnormal free T3 value was $90 \%$ in expired group compared to $75 \%$ to survivors. The value of free T3 did not correlate with the outcome of patients. ${ }^{(51,53,55)}(\mathrm{RR}=2.54)$ 


\section{Thyroxine $\mathbf{T} 4$}

The value of abnormal T4 was $80 \%$ in dead in comparison with $27.5 \%$ in survivors. The value of T4 correlated with the poor outcome of the patients. $(\mathrm{RR}=6.52)$.

\section{Free T4}

Thevalue of abnormal free T4 was $90 \%$ in expired group compared to $17.5 \%$ in survivors. The value of free $\mathrm{T} 4$ correlated with the outcome of patients. $(\mathrm{RR}=30.6)$

\section{CONCLUSION \& LIMITATION OF STUDY}

We recommend the careful interpretation of thyroid functions in critically ill patients and identifying the abnormalities to prognosticate the outcome of patients. The low T3 syndrome is the commonest abnormality seen The thyroid hormones T3, T4, Free T4 are associated with poor outcome and Low T3 T4 syndrome associated with maximum mortality of critically ill patients. The limitation of study was small sample size at single institution and blood sample was taken only at the time of admission.

\section{REFERENCES}

1. J. Larry Jameson, Anthony P. Weetman Disorders of the thyroid gland. 17 th edition Harrison `s Principles of internal medicine

2. P. Reed Larson, Terry. F. Davies, MartinJaen Schlumberger, and Ian. D. Hay. Thyroid Physiology and Diagnostic evaluation of patients with thyroid disorders. Williams Textbook of endocrinology.

3. Inder J Chopra Euthyroid Sick Syndrome: Is it a misnomer. JCE \&M 1997 Vol 82 No 2.

4. Kaptein EM: The effects of systemic illness on thyroid hormone metabolism. IN: Current Issues in Endocrinology and Metabolism: Thyroid Hormone Metabolism - Regulation and Clinical Implications. Ed. S-Y Wu, Boston, MA, Blackwell Scientific Publications, pp. 211-237, 1991.
5. Kaptein EM, Nelson JC: Serum thyroid hormones and thyroid-stimulating hormone. In: Atlas of Clinical Endocrinology, Series Editor, S.G. Korenman, Vol.1, Thyroid Diseases, Volume Editor, M.I. Surks. Philadelphia, PA., Current Medicine, Inc., pp. 15-31, 1999.

6. McIver B, Gorman CA. 1997 Euthyroid sick syndrome: an overview. Thyroid. 7:125-132.

7. Chopra IJ.1982 Euthyroid sick syndrome: abnormalities in circulating thyroid hormones and thyroid hormone physiology in nonthyroid illness (NTI). Med Grand Rounds. 1:201-212.

8. Michalaki M, Vagenakis AG, Makri M, et al: Dissociation of the early decline in serum $\mathrm{T}(3)$ concentration and serum IL-6 rise and TNF-alpha in nonthyroidal illness syndrome induced by abdominal surgery. J ClinEndocrinolMetab 2001; 86:4198-4205

9. Wartofsky L, Burman KD.1982 Alterations in thyroid function in patients with systemic illness: the "euthyroid sick syndrome." Endocr Rev. 3:164 -217.

10. Wong TK, Hershman JM: Changes in thyroid function in nonthyroidal illness. Trends EndocrinolMetab 1992; 3:8-12

11. Hennemann G, Docter R, Krenning EP: Causes and effects of the low $\mathrm{T}$, syndrome during caloric deprivation and nonthyroidal illness: an overview. Acta Med Austriaca 1988;15 (suppl 1):42-45.

12. Gardner DF, Kaplan MM, Stanley CA, et al: Effect of triiodothyronine replacement on the metabolic and pituitary responses to starvation. N Engl J Med 1979; 300:579584

13. Van den Berghe G, de Zegher F, Veidhuis $\mathrm{JD}$, et al: Thyrotropin and prolactin release in prolonged critical illness: dynamics of spontaneous secretion and effects of growth hormone-secretagogues. ClinEndocrinol 1997; 47:599-612 
14. McIver B, Gorman CA: Euthyroid sick syndrome: an overview. Thyroid 1997; $7: 125-132$

15. Chow CC, Mak TW, Chan $\mathrm{CH}$, et al: Euthyroid sick syndrome in pulmonary tuberculosis before and after treatment. Ann ClinBiochem 1995; 32:385-391

16. Wehmann RE, Gregerman RI, Burns WH, et al: Suppression of thyrotropin in the low-thyroxine state of severe nonthyroidal illness. N Engl J Med 1985;312:546-552

17. Becker RA, Vaughan GM, Ziegler MG, et al: Hypermetabolic low triiodothyronine syndrome of burn injury. Crit Care Med 1982;10:870-875

18. Phillips RH, Valente WA, Caplan ES, et al: Circulating thyroid hormone changes in acute trauma: prognostic implications for clinical outcome. J Trauma 1984;24:116119

19. Morley JE, Slag MF, Elson ME. et al: The interpretation of thyroid function tests in hospitalized patients.JAMA 1983;249: 2377-2379.

20. Wadwekar D, Kabadi UM: Thyroid hormone indices during illness in six hypothyroid subjects rendered euthyroid with levothyroxine therapy. Exp Clin Endocrinol Diabetes 112:373-7, 2004

21. Plikat K, Langgartner J, Buettener R, J, Wrede CE Metabolism 2007 Feb 56 (2); $239-244$. 